\title{
Theoretical Debates on the Cultural Consequences of Globalization and Its Implication in the Light of the Ethiopian Culture
}

\author{
Tibebu Shito Kebede \\ Address: 269, Civics and Ethical Studies Department, \\ Debre Markos University, Debre Markos, Ethiopia
}

\begin{abstract}
This paper examined the cultural consequences of globalization in line with different perspectives. The study relied on qualitative research approach along with secondary sources of data so as to analyze the relationship between culture and globalization. Even though people of the world have made closer relations for elongated and continuous periods of time, the pace of interactions, exemplified by the global flows of people, capital, information, commodities, culture etc, has shown significant improvement recently owing to the force of globalization. Thus, globalization, as a multifaceted process, is portrayed by the existence of continuous and multiple linkages on a global scale. One of the interactions by which globalization has been manifested; one is the cultural ties amongst nations. In these processes of cultural connectivity, there exist contact and exchange of elements among the world's cultural rainbow having an array of end results, namely, homogenization, heterogenization, hybridization and polarization thesis.
\end{abstract}

Keywords: Culture, globalization, homogenization, heteroginazation, hybridization, polarization, cultural imperialism

DOI: $10.7176 / \mathrm{IAGS} / 77-02$

Publication date: November $30^{\text {th }} 2019$

\section{Introduction}

Globalization, one of the most complex and controversial notion (Amadi et.al, 2016; Ibrahim, 2013; Hassi and Storti, 2012), is conceptualized as the intensification and expansion of worldwide interaction (Steger, 2017; Khondker, 2004; Scholte, 2002). Even though globalization was initially seen as an economic phenomenon, the force of globalization is not limited to economic spheres alone (Ugbam et.al, 2014; Yankuzo, 2014; Adesina, 2012). Instead, globalization is a multidimensional process exemplified by the existence of cultural, economic and political interactions on a global scale. Moreover, globalization is not a new phenomenon as far as the history of mankind is concerned. The advent of globalization can be traced back to the earliest periods of recorded history (Palmer, 2004) while changing its form, rate, scope and complexity from time to time (Leidner, 2010; Held et.al, 1999). Scholte (2002) further argued that though the term globalization was coined in the 1980s, the historical origin of globalization can be associated with the dawn of mercantilism around the second half of fifteenth century (Ugbam et.al, 2014). Since then, propelled by incredible advancements in communication and transportation technologies (Ugbam et.al, 2014; Brown, 1999), multinational corporations, transnational media institutions, intergovernmental organizations, international non-governmental organizations and national governments (Cuterela, 2012; Thomas, 2007), globalization has significantly amplified the rate of interactions among the world's populace (Wang, 2007). Since globalization has made the interaction and the mutual coexistence of states more inevitable than before (Wang, 2007), almost all states and people of the world are affected remarkably by the process of globalization (Yankuzo, 2014). One of the arenas whereby the effects of globalization have been vividly seen all over the place is culture. However, the cultural consequence of globalization has remained a contentious issue among scholars despite many studies on the correlation between globalization and culture have been conducted (Machida, 2012; Precious, 2010). The focus of this paper is, therefore, to unveil the impact of globalization on the Ethiopian culture in line with different perspectives.

\section{Theoretical Debates on Cultural Globalization}

\subsection{The Homogenization Thesis}

Globalization entails a strong force that promotes cultural homogenization while leading to the eradication of the world cultural rainbow (Ugbam et.al, 2014; Yankuzo, 2014; Machida, 2012; Stefanovic, 2008). Hall (1990) further stated that globalization is all about homogenization or Americanization of the world which in turn erases the globe's cultural diversity. This is because for globalization to continuously exert its influence, it postulates the development, existence and diffusion of a single global culture that transcends beyond varied economic, ethnic, political, racial and religious settings (Brown, 1999). This implies that globalization is not just about the physical interconnectedness of the world. In the words of Lechner (2001), there are multiple reasons through which globalization undermines the cultural diversity of the world. The first rationale is that globalization 
promotes homogenization of culture via transnational companies that creates not only consumerist culture but also identical western lifestyle through their uniform and standardized products termed as "Coca-colonization." Globalization also undermines cultural diversity through "cultural imperialism" whereby the western values, norms and traditions are amplified as universal while posing threat on the survival and identity of local cultures. Thirdly, globalization can be a threat to multiculturalism via "McDonaldization." That is, it is via modern institutions and organizations aimed at the dispersion of fast food culture. Finally, globalization deteriorates cultural diversity through its powerful notion and practice of "Americanization" in which United States of America promote its goods, values, lifestyles and customs. Thus, the author stresses that it is via the forces of coca-colonization, McDonaldization, Americanization as well as cultural imperialism that globalization promotes the existence and dispersion of monoculture, predominantly the American culture.

In its extreme form, there are also other scholars that tend to explicate the impacts of globalization on the Ethiopian culture via cultural imperialism thesis (Tibebu, 2018; Addisu, 2012; Schiller and Van Elteren as cited in Machida, 2012). Here, cultural imperialism implies the process of imposing dominant western culture in general and the American culture in particular against the will of indigenous people or culture which intends at controlling, invading, undermining or destroying other cultures. It is about the expansion and dispersion of the global culture via international media institutions, giant transnational corporations, Microsoft technologies, fashions, films as well as music industries (Tomlinson, 2006) rather than military force like old colonial empires. Tomlinson (2006) further enunciated that what is feared is the subsequent threat of losing the distinct nonwestern cultural values. Along with this perspective, Daramola \& Oyinade (2015) asserted that the end result of cultural imperialism is loss of identity, traditional values as well as self-pride.

Although Ethiopia is the only African country that successfully resisted and defended fascist Italy's colonial invasion, the western neo-imperialists are polluting the native cultural values via media, internet, advertisement and infotainment industries nowadays (Addisu, 2012). In this regard, Rao (2013) further opined that albeit Ethiopia is culturally rich state, the language, music, dance, food habits and outfit of the society is being revolutionized owing to the effects of globalization. On the other hand, the young generation, unlike our ancestors, is failing to conserve and preserve indigenous culture of Ethiopia given that their psychology is significantly affected by xenocentric inclination. This in turn has made them outward looking; the worshiper of the western ways of life as well as the victim of indirect colonialism in the form of cultural imperialism (Tibebu, 2018). In this regard, Enag (2011), while expressing the condition of the youth, held as follows: "A generation that exposed [itself] to cultural imperialism; and who willingly throws [its] native culture. This generation, whose hairstyle and trousers is uncommon, never communicates in native language without mixing English-a submissive generation" (cited in Addisu, 2012, p. 22). Since culture is not only the identity of the people but also a bond that ties them together, lose of one's culture is practically equivalent to lose of one's identity (Ugbam et.al, 2014) which ends up with identity crisis.

As pointed out clearly, the writer asserts that globalization, propelled by socio-economic and political institutions, has played unabated role not only in diluting the Ethiopian culture. But, it is also replacing them with the cultural values of economically and technologically advanced western countries, particularly that of North American and Western Europe. Moreover, the author vehemently argues that globalization has created the young generation that are Ethiopian in blood and color, but western in life style, taste and value via its multifarious instruments such as satellite television, western education, aid, media, internet, tourism, infotainment industries, multinational corporations, intergovernmental organizations and the like. Despite states serious attempt to defend their culture from foreign invasion (Palmer, 2004; Cowen, 2002; Rothkopf, 1997), the existence, expansion and dispersion of the western popular culture not only seems inevitable but also devastates more endangered native cultures (Steger, 2017). Therefore, the relationship between culture and globalization in Ethiopia can be analyzed through homogenization thesis.

\subsection{The Heterogenization Thesis}

The tension between the processes of cultural heterogenization and cultural homogenization is the central problem of these day's global cultural interactions (Appadurai, 1996). Contrary to the notion of homogenization, the central argument of heterogenization thesis, also known as cultural differentialism, is that globalization is not simply about diffusion of the American cultural values and lifestyles. Instead, one culture remains unique and different from the other in spite of the forces of globalization (Hassi and Storti, 2012). Along with this, Sotshangane (2002) asserted that globalization does not always imply cultural standardization and homogenization. Indeed, the process of globalization promotes the mutual co-existence of diverse cultures. While expressing the relationship between globalization and culture, Wang (2007, p. 83) contended that:

Globalization is not simply homogenization; on the contrary, it enhances cultural identity.

First, People are not mere objects of cultural influences, but subjects who can reject or integrate culture. Besides, with the development of science and technology, people are closer than before. The sense of 'togetherness' brought with globalization is not at all in 
conflict with diversity. In the new era of globalization, people become much more concerned about the uniqueness and particularity of their own culture. Cultural identity provides the global significance of local knowledge and the sense of self, community and nation. In terms of science, technology and economic development, globalization reflects somewhat the theory of convergence and hegemonic control, but in deeper sense, it promotes cultural identity.

Moreover, Lechner (2001) stated that globalization promotes cultural diversity for the following rationales: Firstly, globalization fosters multiculturalism through "pluralization" which is typified by cultural contact and exchange across borders which in turn leads to fusion of cultures. Secondly, the flows of culture not only happen in various areas but it takes place in various directions which he termed as "differentiation." The third rationale behind why globalization fosters cultural diversity is that since the integration and dissemination of notions causes "contestation," it is not feasible for the process of globalization to promote cultural standardization. In other words, reactions and resistances from different directions can be regarded as an obstacle for globalization to create a global culture. Besides, there exist differences while interpreting universal norms or traditions as per local context which, in other words, imply "glocalization." As a final point, by virtue of the fact that diversity is considered as positive and promoted both at local and international level these days, it is impossible for a single consumer culture to exist. In other words, globalization fosters "institutionalization" of cultural diversity. In nutshell, globalization brought cultural interaction among world states albeit local resistance prevailed against it. Sotshangane (2002) stated that even though globalization weakens indigenous identities of local people, it also allows and promotes diversity in some respect. This is because, nowadays, there is multiculturalism in the arena of food, media, religion, education and so on. Lynton (2007) further asserted that due to the process of globalization, there are countless voices, multiple choices as well as diverse cultures instead of one say, fewer preferences and single, uniform and global American culture. As said by Wang (2007), because globalization raises the consciousness of the people about their cultural roots than before, they become much more concerned about it. This is to say, people are constantly not only seeking out but also safeguarding their cultural identity in the era of globalization. Hence, irrespective of the strong forces of globalization, cultural differences remain for long. Wang (2007) further stated that if globalization is conceptualized as togetherness and interconnectedness, then the globe is not only more together but also more diverse.

Even though globalization has created an opportunity for Ethiopian culture to be recognized at the global level to some extent, the writer argued that it has more of homogenization impact up on the eastern societies. This is happening due to the unbalanced import and export of cultural items between the developed and developing countries. Moreover, the monopoly of information communication technologies in the hands of the western world places the developing states, like Ethiopia, in a disadvantaged position in the process of globalization leading to cultural invasion and imposition, precisely termed as cultural imperialism. The author, thus, contends that the heterogenization scenario is not adequate enough to contextualize the cultural effects of globalization from the perspective of developing states as it fails to recognize the fact that African cultures are deteriorating by the encroaching agenda of westernization.

\subsection{The Hybridization Thesis}

Holton (2000) argued that some scholars, by examining the strength of each culture across the globe, have found that the relationship between culture and globalization can best be expressed by hybridization thesis. For the proponents of Hybridization approach to cultural globalization, globalization facilitates and promotes the exchange and interaction of different cultures. Nevertheless, hybridization does not necessarily lead to even exchange of cultures (Crothers, 2013). Globalization's cultural consequence implies neither unidirectional cultural standardization that revolves around Westernization or Americanization nor a sharpening polarization that reflects dichotomy between two opposite forces (Ozekin and Arioz, 2014). Instead, the outcome of the global cultural relations is labeled by Hybridization paradigm which represents open ended process of easternization as well as westernization (Pieterse, 2009). Thus, the central argument of cultural hybridization is the continuous process of mixing different cultures so as to create a new and dynamic culture (Iyorza and Ekwok, 2014) as an offshoot of multiple directions of cultural flows (Husted, 2001).

Appadurai (1996) further argued that globalization encompasses five landscapes that shape not only complex interactions between diverse cultures but also the global flow of cultures. These are: "Ethnoscapes" which implies the international flows of people such as visitors, refugees, workers etc. The mechanical as well as informational movement of technologies beyond national boundaries of states, termed as "Technoscapes", is another factor that facilitates cultural exchanges. The third landscape is "Financescapes" which is conceptualized as cross border movement of finance, capitals, loans, grants as well as worldwide flows of foreign direct investment. Additionally, there is "Mediascapes" which refers to existence and dispersion of electronic as well as print Medias throughout the world. The last one is "Ideoscapes" which particularly refers to the international movement of political ideologies, counter ideologies as well as political ideas such as freedom, human rights, 
democracy and the like. As a final point, the global movement of people, technology, finance, media as well as ideology, according to Husted (2001), serves as a "catalyst for the creation of new cultural forms."

As manifested by Iyorza and Ekwok (2014), cultural hybridization happens when people from a particular cultural tradition take bits and pieces from foreign culture, and creates different dialectics, customs, and ways of practicing culture. The upshot of these processes of intercultural exchange is the emergence of global mélange cultures (Ozenkin and Arioz, 2014). In line with this perspective, Crothers (2013) asserted that cultural communication and hybridization is a double fold process. That is, the eastern societies can be affected by the western values, lifestyle, customs etc. like the western ones are influenced by the eastern language, dressing, food etc. Thus, the outcome of cultural mixing cannot be reduced to clear-cut manifestations of cultural sameness or cultural difference (Steger, 2017).

While explaining the process of cultural blending, Iyorza and Ekwok (2014) enunciated that hybridization of culture is the personification of an upcoming synthesized culture whereby people do not "completely abandon their main cultural practices in the wake of encroaching foreign cultures, but adopt the most valuable, cherished and unavoidable elements of their original and inherited cultural practices as they adopt other foreign cultural elements of their choice." Moreover, Pietrese (2009) stressed that cultural hybridization is an amalgamation of various cultures without the need to totally relinquish one's cultural identity. Similarly, in the words of Korhan (2010), hybridization of culture refers to "the possibility of benefiting from other cultures and putting the new knowledge with the old one side by side without losing one's identity completely." Cultural hybridization, which "occurs as a result of the romance between two cultures through transnational media communication technologies" (Iyorza and Ekwok, 2014), is conceptualized as the blending of African, American, Asian as well as European cultural values, norms, traditions etc intended to make global culture as a global mélange (Pietrese, 2009). As pointed out clearly, cultural hybridization refers to a process whereby different cultural elements are combined so as to create new, distinctive, synthesized and trans-local mélange cultures. However, this perspective fails to realize the fact that the global cultural interaction does not always lead to an equivalent exchange of cultural items between the western world and the developing ones. As a result, western cultural values becomes the dominate figure in the process of intercultural blending in that it contributes more and more elements in the creation of the new, synthesized and trans-local cultures. Thus, the hybridization perspective is less likely applicable to contextualize the relationship between culture and globalization in line with the Ethiopian context.

\subsection{The Polarization Thesis}

In addition to convergence, differentialism and hybridization thesis, there are scholars that analyze the tie between globalization and culture via polarization thesis. Polarization thesis implies that cultural globalization is conceived as intense cultural conflict between two contradictory forces working in opposite directions (Holton, 2000). In this regard, Barber (1995) asserted that globalization involves fierce collision between "Jihad" which refers to "bloody holy war on behalf of partisan identity that is metaphysically defined and fanatically defended," and "Mcworld" which implies homogenization of the world through giant multinational corporations, infotainment industries as well as technological advancements. Jihad which is betokened with violent cultural fundamentalism and tribalism is counterpoised against the encroaching westernization and cultural imperialism which is termed as McWorld (Ibid). Even though the increment in the quantity of transnational corporations, the international flow of finance as well as the advancement of transport and communication technologies created more interdependent world than before, there are still conflicts on ethnic, cultural as well as religious basis (Wang, 2007). In accordance with Ozenkin and Arioz (2014), in the contrary to the destructive process of McWorld, Jihad, which is driven by the politics of identity, creates a sense of belongingness to a certain ethnic, cultural or religious group. Consequently, the global cultural relations will inevitably be conflictual. This is by virtue of the fact that "the members of each culture will seek to destroy or eliminate the other" (Crothers, 2013).

In the words of Huntington (1993), for about one and half centuries after the treaty of Westphalia in 1648, there was conflict among kings. After the French revolution in 1789, the principal line of conflict became nations. Then, after Russian revolution in 1917, war among nation states shifted to conflict of ideologies initially among communism, fascism-Nazism and liberal democracy, and then between communism and liberal democracy which was later replaced by conflict of ideologies between United State of America and Union of Soviet Socialist Republics during the cold war period. Thus, the battles of seventeenth centuries between kings, the eighteenth centuries' warfare among nation states, the ideological friction of diverse political ideologies of twentieth century as well as the ideological tension of superpowers during cold war era was conflicts within Western civilizations (Ibid).

In post cold war international politics, however, the fundamental source of conflict is associated with religious and cultural identities of people. Consistent with this perspectives, Said held that cultural dichotomies have been built between Western and non-Western ways of life (cited in Holton, 2000). Similarly, Huntington (1993) stated that the primary source of conflict after the disintegration of Union of Soviet Socialist Republics 
(USSR) in 1991 is not economic or ideological. Instead, global politics will be characterized by the existence of conflict on the basis of cultural fault lines which is termed as "clash of civilizations." This is because "the members of each group seek to expand or defend their cultural turf" (Crothers, 2013). Moreover, polarization thesis prefigures that the global cultural relations are generating and will likely generate cultural violence and fragmentation which in its extreme form portrayed by cultural war between the western world on one hand and its opponents on the other hand. However, the polarization perspective missed the point that the African culture is not capable enough to challenge the dominant and the encroaching western cultural values. So, this perspective is not as such relevant to explain the cultural consequences of globalization in Ethiopia.

\section{Conclusion}

Assessing the impact of globalization on culture is one of the most contentious issues. This is due to the fact that regardless of large numbers of studies on the subject of globalization, there is no unanimity among scholars as far as its real impact on culture is concerned. However, globalization's cultural consequence can be analyzed through four main perspectives, namely, homogenization, heterogenization, hybridization and polarization thesis. The homogenization perspective to cultural globalization holds that globalization is a force leading to the deterioration of the global cultural rainbow while promoting the triumph of a single and uniform global culture, particularly the western culture. In doing this, globalization employs different instruments such as Medias, internet, fashion industries, film industries, transnational corporations and so forth. In its extreme form, the upshot of the global cultural exchange is cultural imperialism which in turn prefigures loss of self pride; deterioration of cultural identity as well as identity crisis. On the contrary, the proponents of heteroginazation thesis vehemently believe that globalization does not necessarily lead to the homogenization of culture. Instead, globalization enhances cultural identity by promoting mutual existence of multiple cultures. To be specific, irrespective of the strong forces of globalization, each culture not only maintains its particularity but also remains different for long.

The mid way between homogenization and heteroginazation approach is hybridization thesis which betokens globalization with neither clear cut cultural uniformity nor cultural uniqueness. Bearing in mind that hybridization does not always lead to even exchange of cultures, the global flow of culture is a two way process whereby the eastern world is affected by the western world and vice versa. In nutshell, hybridization of culture is about the mélange of diverse cultures so as to form new, unique and synthesized cultures without the need to give up one's cultural identity completely. In addition to homogenization, heteroginization and hybridization approach, scholars like Barber, Huntington and Said tend to associate the cultural consequences of globalization with polarization thesis. The central argument of polarization approach to cultural globalization is that the global cultural relations are portrayed by intense cultural clash between two paradoxical forces, namely the western and eastern civilization, moving in opposite directions. Unlike the pre cold war era, the inherent source of tension and fragmentation in the post 1990's international relations lies on ethnicity and cultural identities of the people. In other words, cultural conflict is and will be the manifestation of the contemporary global politics. Globalization in general and cultural imperialism in particular is introducing, spreading and imposing alien practices and values up on developing states leading to cultural invasion, precisely termed as cultural imperialism or cultural colonialism. What is surprising is that some of these traditions are not even inclusively accepted and practiced by the whole westerners. To sum up, the writer vehemently argues that the cultural effects of globalization in Ethiopia can be manifested via homogenization thesis.

\section{References}

Addisu, H. (2012), "Modes of Cultural Imperialism as Reflected in the Narratives of Daniel Kibret", Unpublished master's thesis, University of Addis Ababa. Retrieved July 01, 2017, from etd.aau.edu.et/ browse?type $=$ author\&sort $b y=1 . . . r p p . . . A d d i s u \% 2 C$.

Adesina, O. (2012), "The Negative Impact of Globalization on Nigeria", International Journal of Humanities and Social Science 2(15), 193-201.

Amadi, L., Imoh-Ita, I., \& Obomanu E. (2016), "Culture Mutation in the Era of Globalization: Africa in Perspective", International Journal of History and Cultural Studies (IJHCS), 2 (1), 25-38.

Appadurai, A. (1996), "Modernity at Large: Cultural Dimensions of Globalization”, Minneapolis: University Of Minnesota Press.

Baber, B. (1995), "Jihad vs. Mc world”, New York: Ballantine Books.

Brown, K. (1999), "Globalization and Cultural Conflict in Developing Countries: The South African Example", Indiana Journal of Global Legal Studies, 7(1), 225-256.

Cowen, T. (2002), "Creative destruction: How globalization is changing the world's cultures", Princeton: Princeton University Press.

Crothers, L. (2013), "Globalization and American Popular Culture (3th Ed.)", United States of America: Rowman and Littlefield publishers, INC. 
Cuterela, S. (2012), “Globalization: Definition, Processes and Concepts”, Romanian Statistical Review, 60(4), 137-146.

Daramola, I., \& Oyinade, B. (2015), "Impact of Cultural Globalization on Africa: The Role of Western Media", International Journal of Education and Research, 3(3), 31-46.

Hall, E. (1990), "The Local and the Global: Globalization and Ethnicity, In A. D. King (Ed.), Culture, Globalization and the World System: Contemporary Conditions for the Representation of Identity (pp. 1940)", Minneapolis: University of Minneapolis press.

Hassi, A., \& Storti, G. (2012), "Globalization and Culture: The Three H Scenarios", Intech open science publisher, 1-20.

Held, D., McGrew, A., Goldblatt, D., \& Perraton, J. (1999), "Global Transformations: Politics, Economics and Culture", Stanford: Stanford University Press.

Holton, R. (2000), "Globalization's Cultural Consequences", American Academy of Political and Social Science, Vol. 570, 140-152.

Huntington, S. (1993), “The Clash of Civilizations?”, Foreign Affairs, 72 (3), 22-49.

Husted, B. (2001), "Cultural Balkanization and Hybridization in an Era of Globalization: Implications for International Business Research", Retrieved March 05, 2018, from citeseerx .ist.psu.edu/viewdoc/download?doi=10.1.1.200.5621\&rep=rep1.

Ibrahim, A. (2013), "The Impact of Globalization on Africa", International Journal of Humanities and Social Science, 3(15), 85-93.

Iyorza, S., \& Ekwok, L. (2014), "Global Media and Cultural Hybridization in the $21^{\text {st }}$ Century in Nigeria", Journal of Social Sciences (COES\&RJ-JSS), 3(3), 408-416.

Khondker, H. (2004), "Glocalization as Globalization: Evolution of a Sociological Concept", Bangladesh eJournal of Sociology, 1(2), 1-9.

Korhan, D. (2010), "Globalization, Culture, and the Roles of Media", Retrieved March 10, 2018, from www.duygu korhan.com/articles/henrikfinal.pdf.

Lechner, F. (2001), “Globalization Issues: Does Globalization Diminish Cultural Diversity?”, Retrieved January 06, 2018, from sociology.emory.edu /faculty/ globalization /issues 05. html.

Leidner, D. (2010), “Globalization, Culture and Information: Towards Global Knowledge Transparency", Journal of Strategic Information Systems, 19, 69-77.

Lynton, M. (2007), "Globalization and Cultural Diversity", Retrieved January 06, 2018, from https: //yaleglobal.yale.edu/content/globalization-and-cultural-diversity.

Machida, S. (2012), "Does Globalization Render People More Ethnocentric? Globalization and People's Views on Cultures", American Journal of Economics and Sociology, 71 (2), 436-469.

Ozekin, M., \& Arioz, Z. (2014), "Beyond Cultural Imperialism: Cultural Globalization as Hybridization", Journal of World of Turks, 6(3), 179-191.

Palmer, T. (2004), "Globalization and Culture: Homogeneity, Diversity, Identity, Liberty”, Potsdam: The Liberal Institute of the Friedrich Naumann Foundation.

Precious, O. (2010), "Globalization and the Future of African Culture", Philosophical Papers and Reviews, 2(1), $1-8$.

Rao, R. (2013), "Globalization and its Impact on Ethiopia”, The Business \& Management Review, 3(4), 213-217.

Rothkopf, D. (1997), “In Praise of Cultural Imperialism?”, Foreign Policy, 107, 38-53.

Scholte, J. (2002), "What is Globalization? The Definitional Issue -Again", Centre for the Study of Globalization and Regionalization (CSGR): Working Paper No. 109/02. Retrieved February 10, 2018, from wrap.warwick.ac.uk/2010/1/WRAP_Scholte_wp10902.pdf.

Stefanović, Z. (2008), "Globalization: Theoretical Perspectives, Impacts and Institutional Response of the Economy", The Facta Universitatis Series: Economics and Organization (FU Econ Org), 5(3), 263 - 272.

Steger, M. (2017), "Globalization: A Very Short Introduction ( $4^{\text {th }}$ ed.)", United Kingdom: Oxford University Press.

Sotshangane, N. (2002), "What Impact Globalization has on Cultural Diversity?", Alternatives: Turkish Journal of International Relations, 1(4), 214-231.

Thomas, G. (2007), "Globalization: The Major Players, in G. Ritzer (Ed.), The Blackwell Companion to Globalization (pp. 84-107)", Malden: Blackwell Publishing Ltd.

Tibebu, S. (2018), "The Impact of Globalization on the Ethiopian Culture", Unpublished Master's Thesis, Punjabi University Patiala.

Tomlinson, J. (2006), "Globalization and Culture", Retrieved January 15, 2008, from cite seerx. $i$ st.psu.edu/viewdoc /download?doi=10.1.1.465.9581\&rep=rep1...pdf.

Ugbam, O., Chukwu, B., \& Ogbo, A. (2014), "The Effects of Globalization on African Culture: The Nigerian Perspective", IOSR Journal of Business and Management (IOSR-JBM), 16(4), 62-71.

Wang, Y. (2007), "Globalization Enhances Cultural Identity”, Intercultural Communication Studies, 14 (1), 83 - 
86.

Yankuzo, K. (2014), "Impact of Globalization on the Traditional African Cultures", International Letters of Social and Humanistic Sciences, 15, 1-8. 